\title{
Tell Me Lies Again: Katzelmacher Pequenas guerras entre amigos
}

\section{Alexandra Moreira da Silva}

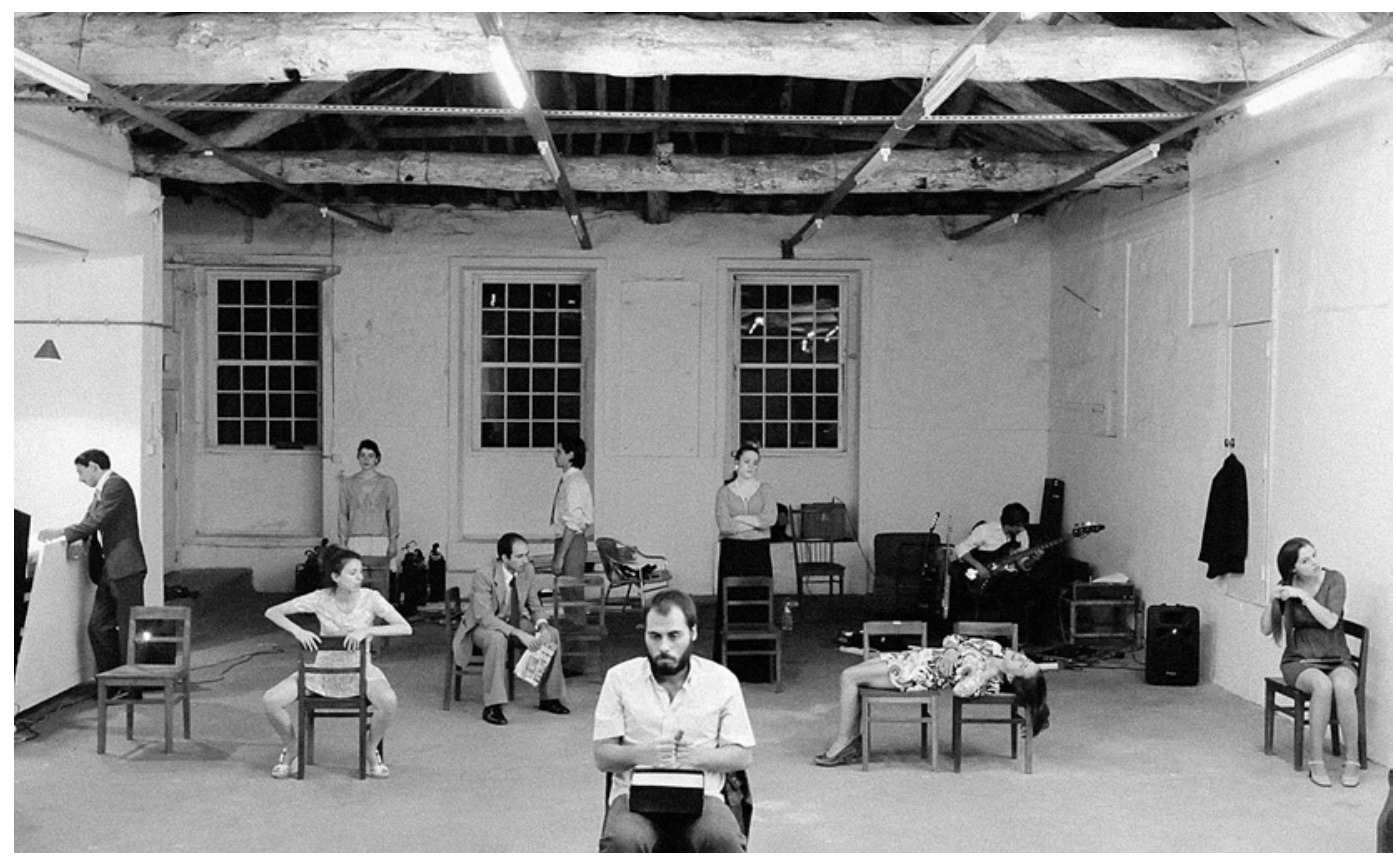

Título: Katzelmacher (1968/1969). Autor:Rainer Werner Fassbinder. Tradução:Ricardo Braun. Dramaturgia, cenografia e encenação: Luis Araújo e Ricardo Braun. Figurinos:Sara Pazos. Desenho de luz: Pedro Cunha. Música:maybe the next one. Interpretação:Adriana Vaz de Carvalho, Afonso Santos, Ana Santos, António Parra, Mafalda Banquart, Marta Cunha, Ricardo Bueno, Rita Gigante, Sérgio Sá Cunha, Tiago Moreira e Manuel Molarinho. Produção:0TTO. Local e data de estreia:Lófte, Porto, 19 de Setembro de 2012.

Em 1967, Peter Brook realizava Tell Me Lies, filme entre o documentário e a ficção a partir do espectáculo US (Royal Shakespeare Company, Aldwych Theater, 1966) que se apresentava como uma interrogação aos contemporâneos sobre a guerra no Vietname. Proposto em Cannes em 1968, onde nunca viria a ser apresentado, o filme recebe, no mesmo ano, a Menção especial do Júri no Festival de Veneza e tem uma brevissima apresentação nas salas de cinema'. Em 1968, Rainer Werner Fassbinder escreve e co-encena Katzelmacher para o Action-Theater, peça que viria a ser adaptada para o cinema no ano seguinte pelo próprio encenador e realizador. 0 filme, que retrata o impacto da chegada de um trabalhador grego a uma comunidade da província da Baviera, tem estreia em Outubro de 1969 durante a Semana de Cinema de Mannheim e obtém o reconhecimento generalizado da crítica especializada e do público.
Que relação existe entre estes dois projectos? Aparentemente nenhuma, a não ser o facto de se tratar de duas peças que estão na origem de dois filmes, e de ambos terem tido lugar no período dos conturbados movimentos estudantis do final dos anos 60. Mas, na verdade, há algo maior que os une: a partir de dois problemas concretos da sociedade da época, Brook e Fassbinder procuram reflectir sobre o abismo que existe entre o desejo de liberdade e a hipocrisia do mundo em que vivem.

Não será por acaso que a novissima companhia do Porto - 0TTO - escolheu para a sua primeira produção, em Setembro de 2012, a obra Katzelmacher ${ }^{2}$ do então muito jovem (23 anos) Rainer Werner Fassbinder. Luis Araújo e Ricardo Braun reuniram à sua volta um grupo de cerca de quinze jovens actores e criativos de origens e formações diversas, todos com "vontade de fazer". E,
Katzelmacher,

de Rainer Werner

Fassbinder,

enc. Luis Araújo

e Ricardo Braun, Produção 0TTO, Lófte, Porto, 2012,

foto de ensaio

(Afonso Santos, Mafalda Banquart,

Rita Gigante,

Sérgio Sá Cunha, Adriana Vaz de Carvalho, Manuel Molarinho,

Ana Santos, Ricardo Bueno Marta Cunha

e António Parra), fot. Sara Pazos.

Restaurado em 2011, Tell Me Lies regressou às salas de cinema em Outubro de 2012.

De acordo com a informação disponivel na CETbase - Teatro em

Portugal, a peça

Katzelmacher foi levada à cena em 1983 pelo CITAC, numa encenação de Mário Barradas, e novamente em 1997, pela Barraca, com o titulo 0 bode expiatório com tradução de Maria Carlota A. da Guerra e encenação de Maria do Céu Guerra.

Alexandra Moreira da Silva é professora da Faculdade de Letras da Universidade do Porto e investigadora do Instituto de Literatura Comparada Margarida Losa da mesma

universidade. É tradutora e dramaturgista, e fo distinguida em 2011 pelo governo francês com título de Chevalier dans l'ordre des Palmes Académiques. 


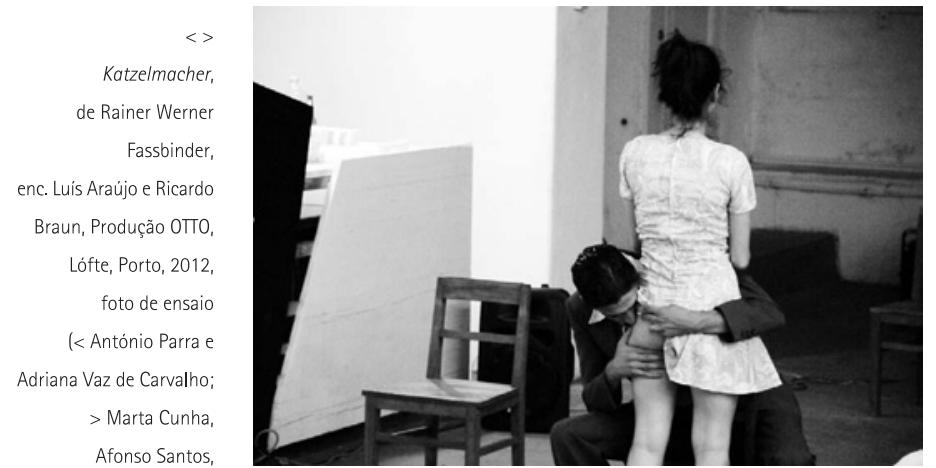

Adriana Vaz de Carvalho,

Rita Gigante,

Mafalda Branquart,

Ricardo Bueno,

Sérgio Sá Cunha,

Ana Santos,

Manuel Molarinho,

António Parra)

fot. Sara Pazos.

"neste sistema doente" onde as pessoas se relacionam "com o dinheiro e pelo dinheiro", fizeram-se "corpos "poniveis" e disponíveis" (Araújo / Braun 2012: 4),

oferecendo todo um Verão dos seus vinte e poucos anos a este projecto. 0 TUP (Teatro Universitário do Porto) e a ESMAE (Escola Superior de Música e Artes do Espectáculo) acolheram os ensaios, e o espectáculo teve estreia no $2^{\circ}$ piso do n 43 da Rua dos Caldeireiros (Porto), na sala ampla, de paredes brancas e janelas de guilhotina do Lófte espaço normalmente destinado a exposições, conferências e performances (onde tiveram lugar alguns dos espectáculos do TRAMA, Festival de Artes Performativas promovido pelo Museu de Serralves, cuja suspensão, este ano, deixou o Outono portuense surpreendido e menos surpreendente), dificilmente adaptável às necessidades técnicas de um espectáculo de teatro. Mas era preciso "fazer", e fez-se.

À esquerda, o balcão de um bar, à direita, os sofás (os espaços intimos); cadeiras espalhadas vão permitir construir vários espaços, exteriores e interiores. Como já fizera Fassbinder e por razões semelhantes, ou seja, "num contexto em que não era possivel pagar bem, em que se fazia teatro por prazer e pela vontade de fazer parte de um grupo", a opção passa por ter "toda a gente em palco o tempo todo, para que, no mínimo, toda a gente esteja em palco a mesma quantidade de tempo" (ibidem). A decisão é nobre e - mais importante - dramaturgicamente possivel. Mas, a verdade, é que nem sempre funcionou. 0 espaço (demasiado) amplo para um teatro que, apesar de tudo, se quer intimo, onde o desenho de luz de Pedro Cunha ficou seriamente comprometido pela ausência de condições técnicas, acabou por instalar alguma dispersão nem sempre fácil de resolver para os actores e para o público.

Ainda assim, a dramaturgia rigorosa de Luis Araújo e Ricardo Braun, construída a partir de elementos da peça de elementos do filme e de uma cena de um outro filme do realizador alemão, Faustrecht dar Freiheit ( 0 direito do mais forte à liberdade, de 1975), permitiu criar um desenho cénico legível e quase sempre claro em termos de movimentos e de intenções, para o qual muito contribuiu a música dos promissores e versáteis Manuel Molarinho (que integra o elenco, assumindo uma das personagens, Klaus) e Sofia Arriscado, do projecto musical maybe the next one.

Os figurinos de Sara Pazos situam-nos nos anos 70, criando uma interessante distância relativamente à mais imediata e talvez expectável contemporaneidade, ao mesmo tempo que vai convocando imagens do filme Katzelmacher (1969). No entanto, esta distância temporal é interrompida por duas decisões dramatúrgicas, subtilmente introduzidas:

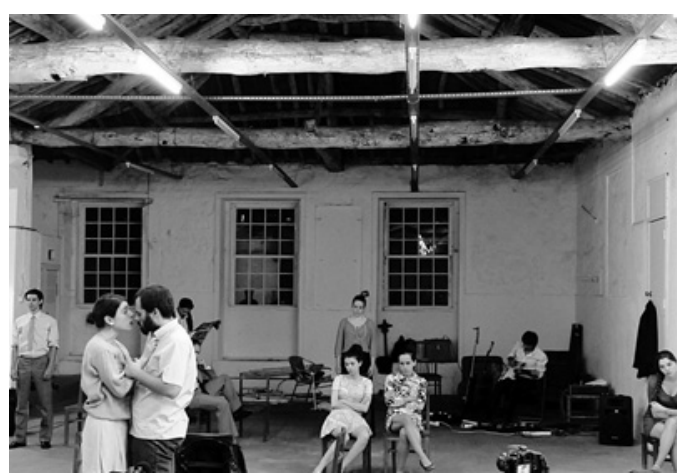

os marcos de que tanto falam estas personagens passam a ser, objectivamente, euros, e, na cena da igreja, um discurso de Angela Merkel pronunciado em Outubro de 2010, onde a chanceler alemã reconhece a falência de uma sociedade multicultural na Alemanha contemporânea reproduzido no belíssimo e informado programa do espectáculo, confunde-se, sob os diálogos das personagens, com a eventual homilia do padre.

0 jovem elenco deste espectáculo revelou-se exemplar na dedicação, na seriedade do trabalho, no tratamento do texto. Talvez estivéssemos à espera de ver actores mais experientes, com uma maturidade e uma assertividade no jogo e na contra-cena mais evocativos do mundo duro e paradoxal dos textos e sobretudo dos filmes de Fassbinder. No entanto, a vantagem deste elenco consiste precisamente na ambiguidade que a sua leveza transporta. Aposta-se no ritmo lento da elocução, nas pausas onde se vê germinar a crueldade banal das relações humanas e a violência que rapidamente circula de forma subterrânea neste grupo e que mais não é do que uma pequena amostra daquilo a que o autor alemão chamava "o síndrome do fascismo quotidiano". A dispersão ocasional a que há pouco me referia, resulta em pontuais relaxamentos que não favorecem a atmosfera do espectáculo, cuja leveza não deve excluir a tensão que o jogo duplo - a mentira compulsiva - da maior parte destas personagens necessariamente provoca. Ainda assim, parece-me evidente que o trabalho no seu conjunto promete novos desenvolvimentos deste "querer fazer" sério e responsável.

Comecei e termino com Peter Brook. Se, como refere o encenador e realizador inglês "o teatro não pode mudar o mundo", a verdade é que "ao manter-se perto deste mundo em evolução constante, o próprio mundo pode mudar o teatro" (Brook apud Duval / Wemaere 2012: 13), ou seja, pode transformá-lo num lugar de reflexão - e não de lição -, de questionamento das nossas contradições e comportamentos, do nosso silêncio. É também disto que nos fala a OTO com este espectáculo. Até porque "nem tudo é branco ou preto. Pelo contrário, o verdadeiro compromisso consiste em tentar aceder a todas as camadas de cinzentos" (ibidem: 42).

\section{Referências bibliográficas}

ARAÚJO, Luis / BRAUN, Ricardo (2012), "É melhor cometer erros novos do que perpetuar os antigos até à inconsciência", in Programa do espectáculo Katzelmacher, Porto.

DUVAL, Gilles / WEMAERE, Severine (2012), Peter Brook et le Vietnam, Tell Me Lies, Paris, Collection des Fondations. 